Canadian Journal of Higher Education Revue canadienne d'enseignement supérieur

Volume 45, No. 4, 2015, pages 42 - 62

\title{
A Large, First-Year, Introductory, Multi- Sectional Biological Concepts of Health Course Designed to Develop Skills and Enhance Deeper Learning
}

Coral L. Murrant, David J. Dyck, James B. Kirkland, Genevieve S. Newton, Kerry L. Ritchie, Justine M. Tishinsky, and William J. Bettger

University of Guelph

Nicolette S. Richardson

York University in Toronto

\begin{abstract}
Large first-year biology classes, with their heavy emphasis on factual content, contribute to low student engagement and misrepresent the dynamic, interdisciplinary nature of biological science. We sought to redesign a course to deliver fundamental biology curriculum through the study of health, promote skills development, and encourage a deeper level of learning for a large, multi-section first-year class. We describe the Biological Concepts of Health course designed to encourage higher-order learning and teach oral communication and independent learning skills to large numbers of first-year students. We used the Blooming Biology Tool to determine the cognitive skills level assessed in the newly developed course and the courses it replaced. This evidence-based approach demonstrated that our new course design achieved the goal of encouraging a deeper level of cognition, and further, successfully introduced both oral communication and independent learning skills in large first-year classes.
\end{abstract}

\section{Résumé}

En mettant l'emphase sur un contenu factuel, les grandes classes de biologie de première année contribuent au faible engagement des élèves et donnent une représentation imprécise de la nature dynamique et interdisciplinaire des sciences de la biologie. Afin d'offrir un programme fondamental en biologie 
par l'étude de la santé, de promouvoir le perfectionnement des compétences et d'encourager un niveau d'apprentissage marqué, nous avons repensé un cours pour une grande classe de première année contenant plusieurs sous-groupes. Nous décrivons le cours « Biological Concepts of Health » conçu pour encourager l'apprentissage supérieur, ainsi que pour enseigner la communication orale et les habiletés d'apprentissage individualisé à un grand nombre d'étudiants de première année. Pour déterminer le niveau d'habiletés cognitives évalué dans ce cours nouvellement conçu et les cours qu'il remplace, nous avons utilisé le «Blooming Biology Tool ». Cette approche éprouvée démontre que ce nouveau cours a atteint son but d'encourager l'approfondissement des connaissances et, par ailleurs, a réussi à introduire la communication orale, de même que les habiletés d'apprentissage individualisé aux grandes classes de première année.

\section{Introduction}

Many first-year science courses at medium to large institutions offer large class sizes in the first year, with a heavy emphasis on factual content and memorization. Both attributes have contributed to low student engagement (as indicated by the National Survey of Student Engagement (NSSE)) and a misrepresentation of the dynamic, interdisciplinary, and powerful nature of biological science. An emerging strategy for enhancing first-year student learning and engagement is to use small group seminar format courses (Murray \& Summerlee, 2007). This format, while optimal, cannot be offered to every first-year science student, given that the seminar course design requires a small number of students per class (approximately 15), and the faculty resources necessary to offer such seminar courses to approximately 1,800 students per year are not sustainable. Thus, we sought to redesign a first-year introductory biology course for every student, one that would enhance student learning and facilitate the development of the skills and attributes important in the study of biology (National Research Council, 2003).

Our goals in this paper are (i) to share with other educators the structure of our newly designed first-year introductory biology course, which emphasizes skills and attributes as well as content, and (ii) to validate the pedagogical value of the new course. To do this, we will first consider the two introductory biology courses that were replaced and will describe the linked-course model that was created, whereby three courses teach biology at different scales. Following this, we will consider in detail one of the three courses in the linkedcourse model, Biological Concepts of Health, and will describe how we used the Blooming Biology Tool to empirically determine whether we had designed a course that expected higher-order learning, and whether we were able to show that students could meet these higher expectations (based on a normal class average with a low failure rate); if they could, we would then infer that we had encouraged higher-order learning. Further, we will show how this analysis can be used to inform the continued evolution of the course's design.

\section{Background}

\section{The Courses to be Replaced: Biology I and Biology II}

The two courses to be replaced, Biology I and Biology II, were previously offered in succession, each taught by four professors in two- to three-week intervals. Biology I pro- 
vided an introduction to the scientific study of life. The course explored the basic challenges that animals, microbes, and plants face in their effort to survive, and the diversity of evolutionary solutions that have evolved as a consequence. The course was designed to emphasize the dynamic process of discovery, highlight relevant and controversial topics in biology, and introduce the general principles necessary for more advanced biology courses. Lectures formed the delivery mechanism, and students' grasp of the course material was assessed through tests, tutorials, and a written assignment regarding science in the primary literature and the popular media (Figure 1). Biology II continued the scientific study of life introduced in Biology I and explored some of the basic challenges that organisms-from microbes to plants and animals-face in order to survive and reproduce. Biology II introduced the challenges of growth and development, reproduction, and response to the environment, and the variety of solutions living systems have developed. The course concluded with life in the global context to demonstrate how organisms are interdependent and form a global living system that not only is sensitive to changes in the environment but also directly influences it. The course was designed to emphasize the dynamic process of discovery, highlight relevant (and at times controversial) topics in biology, enable interpretation of the primary scientific literature, and introduce some of the general principles necessary for more advanced courses. The delivery mechanism was, again, lectures, and students were assessed through tests, tutorials relating to their assessment of the primary literature, online discussions on the course website, and a semester assignment requiring them to produce PowerPoint slides related to a critique of two primary-literature journal articles (Figure 1). The learning objectives for these courses can be found in the supplementary material (see Appendix 1).
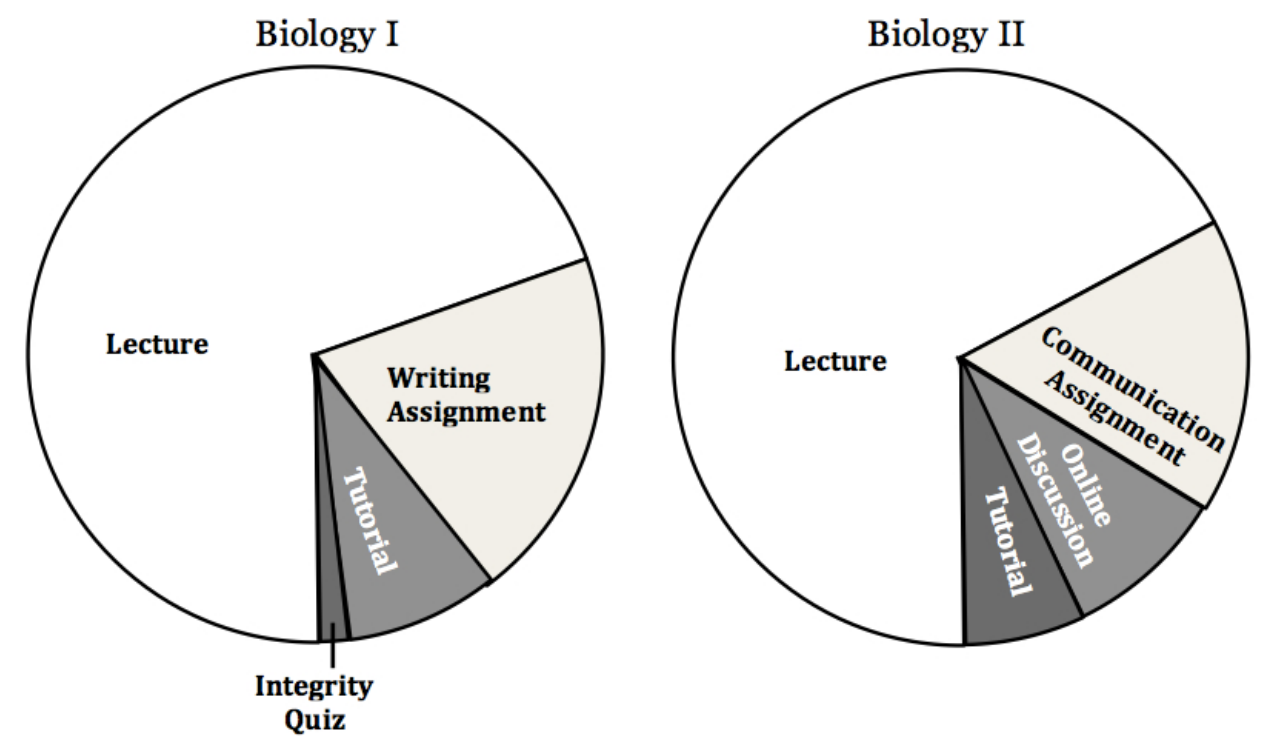

Figure 1. Biology I and Biology II. A pictorial representation of the different course components of the Biology I and Biology II courses. The size of each component represents the percentage that it contributed to student assessment. Biology I consisted of lectures, with a test component worth $70 \%$ of the student's total assessment, a writing assignment worth $20 \%$, a tutorial worth $9 \%$, and an integrity quiz worth $1 \%$. Biology II consisted of lectures, with a test component worth $67 \%$, a communication assignment worth $15 \%$, online discussions worth $10 \%$, and tutorials worth $8 \%$. 
These courses suffered from issues common to large first-year biology courses. These included low student engagement, as well as student feedback indicating dissatisfaction with the course structure, particularly the involvement of multiple faculty members, which some students felt led to a lack of continuity and an apparent lack of connection between lectures and tutorials; there was also a lack of focus on specific skills development.

\section{Development of the Linked-Course Model}

Rethinking and redesigning the first-year introductory biology experience using a team of instructors and teaching technicians led to a linked-course model whereby two courses were replaced by three, all of which needed to be taken in the students' first year as part of their normal 10-course load. Each of the three courses explored different scales of biology, from molecules to cells, tissues, systems, individuals, and populations. In a given semester, students were in one of the three courses for nine weeks of a 12-week semester, then worked in interdisciplinary groups of six (two from each course) for the last three weeks, considering a larger biological problem from the point of view of each course (Figure 2). Through the linked-course model, the three courses were set up to deliver the 18 biological concepts that define modern biology in the $21^{\text {st }}$ century and the eight skills and attributes of a biologist (National Research Council, 2003). The skills and attributes that were taught, reinforced, and assessed are listed in Table 1. Two of the skills and attributes were assigned to be taught and assessed in each of the courses, and two were taught and assessed within the interdisciplinary project.

Table 1.

The Skills and Attributes* that were Taught, Reinforced, and Assessed at Least Once in the Linked-Course Model

\begin{tabular}{ll}
\hline Skill and Attribute & Description of Skill and Attribute \\
\hline Independent learning & $\begin{array}{l}\text { Time management, learning styles, effective reading, note } \\
\text { taking, concept mapping }\end{array}$ \\
Process of biological inquiry & $\begin{array}{l}\text { Modes of inquiry, hypotheses and predictions, experimen- } \\
\text { tal design, constructing arguments, bioethics }\end{array}$ \\
Information management and & $\begin{array}{l}\text { Identifying and accessing information sources, referencing } \\
\text { evaluation }\end{array}$ \\
information, assessing quality of information \\
Variability, descriptive statistics, comparing groups, \\
Written communication & $\begin{array}{l}\text { assessing accuracy and precision of facts } \\
\text { Structure of scientific papers, using outlines, logic and }\end{array}$ \\
Oral communication & Planning a presentation, delivery styles, using visual aids \\
Working in teams & Planning, task management, professionalism \\
Integrative analysis & Concept mapping, evaluating interactions \\
\hline
\end{tabular}

* Two skills and attributes were assigned to each course, and two skills and attributes were assigned to the interdisciplinary project component. 


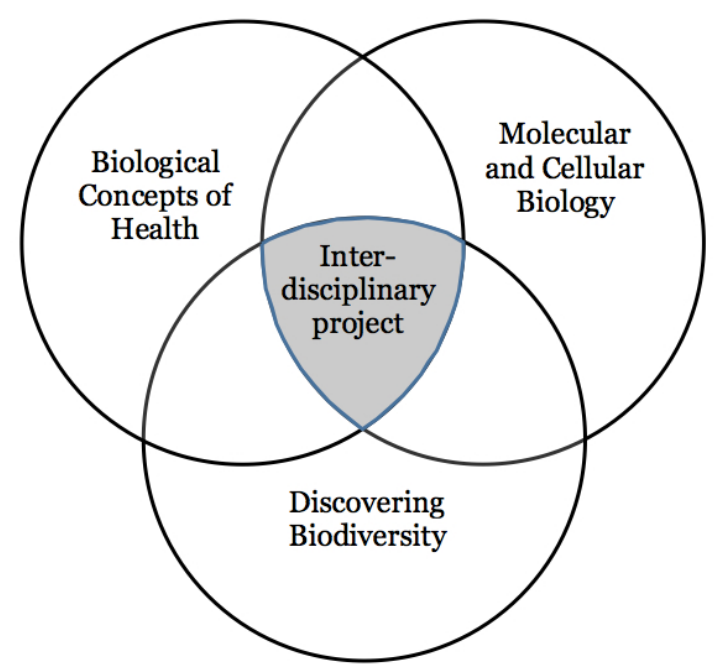

Figure 2. The linked-course model. A pictorial representation of the linked-course model, whereby three courses, which span the scales of biology from molecules to populations, are taught for nine weeks, after which students are placed in groups of six (two from each course) for the final three weeks, to apply their knowledge to real-world problems in an interdisciplinary project.

The three courses offered in the linked-course model each teach within different scales of biology that span from molecules to cells, tissues, systems, individuals, and populations. Introduction to Cellular and Molecular Biology covers material at the molecular and cellular level. The Biological Concepts of Health course deals with cells, tissues, systems, and individuals. The Discovering Biodiversity course addresses individuals and populations.

\section{The Biological Concepts of Health Course}

A team of veteran instructors, teaching technicians, and students redesigned the course, guided by internal documents that steer course design at the University of Guelph (primarily Kenny \& Desmarais, 2012; also Desmarais, 2012). The challenge in the linked model was to develop, in each case, a course that would enhance student learning and engagement, teach and assess at least two of the eight skills necessary for biologists (Table 1), emphasize inquiry, encourage a deeper level of learning, and deliver a specified number of the biological concepts that define modern biology in the $21^{\text {st }}$ century. The specific tasks for the Biological Concepts of Health course were to: introduce each of the 18 biological concepts that define modern biology in the $21^{\text {st }}$ century; reinforce eight specific concepts (listed in Table 2) by teaching about tissues, systems, and individuals through the topic of health; and teach, develop, and assess independent learning and oral communication skills. The most difficult design consideration was to create a course that would meet the above criteria for 1,800 first-year students per year (600 per section in three sections).

The Biological Concepts of Health course was designed for all first-year BSc students at the University of Guelph; however, it serves equally well as an entry-level university course in the study of biology generally, including as a foundational course for those pursuing majors in health science. The course is, in fact, open to students at all levels of undergraduate education and pursing all degree majors. Increasingly, upper-level non-BSc students are selecting the course as one of their science electives.

A primary goal of the first-year Biological Concepts of Health course is to engage students in the advanced educational/learning process. In general terms, this means providing 
a course that helps students to engage in conversations that will challenge-and ultimately shape-their view of themselves and of the world around them. Specifically, this means that students are asked to examine, and are encouraged to discuss, their own health and their changing perspectives on health and healthcare. The course encourages an understanding of the biopsychosocial model of health and healthcare: health is rooted in the physiology of the individual and is an individual human right and responsibility-but the implications of this reverberate throughout families/social networks/populations, communities, ecosystems, and the biosphere. The biopsychosocial model of health dominates the views on health and healthcare that exist in the spheres of public health, the allied health professions, and global political agencies; this model contrasts with the biomedical model of health that has driven the physician-based healthcare system in Canada for the past 50 years or more.

The course objectives (see Table S1 in the supplemental materials) were delivered through multiple different course components (Figure 3). Two lectures per week (augmented with an online series of "lecture afterthoughts") were the vehicle to increase engagement, emphasize inquiry, encourage a deeper level of learning, and support integrative thinking and scientific inquiry skills. One tutorial per week offered the opportunity to teach, reinforce, and assess oral communication skills and reinforce independent learning, writing, group work, and information management skills. Two labs per semester provided the space to teach, reinforce, and assess independent learning skills and to reinforce writing, numeracy, and integrative thinking skills. The interdisciplinary project provided space to teach, reinforce, and assess teamwork and integrative analysis. The background quiz was administered to students in the first week of classes to give them feedback as to whether they required remedial biochemistry. The course was supported by a customedition textbook augmented with several essays/chapters constructed specifically for the course and for the online skills and attributes workshops.

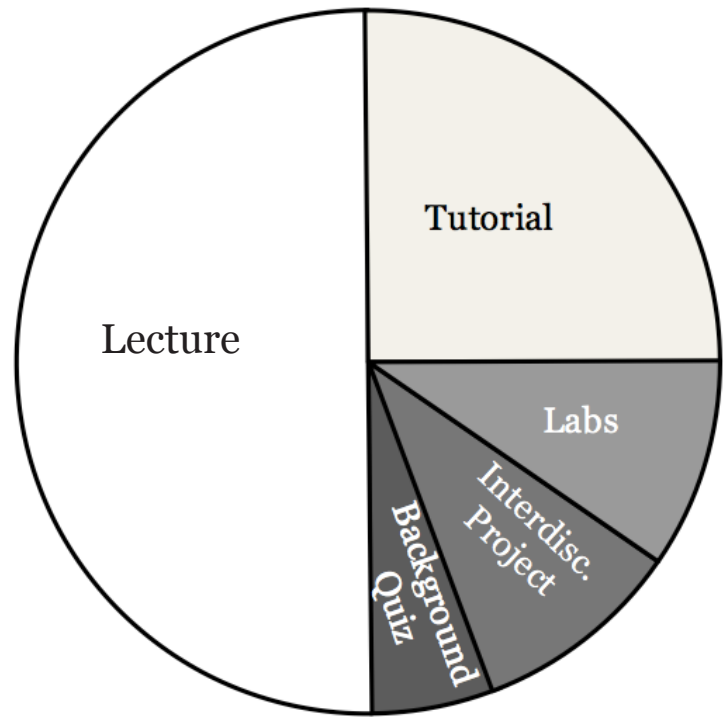

Figure 3. Biological Concepts of Health. A pictorial representation of the different components of the Biological Concepts of Health course. The size of each component represents the percentage that each contributes to student assessment. The Biological Concepts of Health course consisted of lectures, with a test component worth $50 \%$ of the student's total assessment, laboratories worth $20 \%$, tutorials worth $25 \%$, the interdisciplinary project worth $10 \%$, and biochemistry quizzes worth $1 \%$. 
Lectures. The lectures were the vehicle through which we wanted to increase engagement, emphasize inquiry, and encourage a deeper level of learning, where the locus of health would be firmly rooted in physiology and not psychology. We reduced the number of lectures to two per week in order to make room for other enriched, non-lecture activities.

The lecture series was enhanced using a variety of techniques, and the engagement was increased through framing of the lecture material. Lectures were enhanced by asking questions and encouraging students to think and reflect, especially about topics relevant to themselves and topics about which they might have had preconceived ideas, such as the definitions of health, wellness, and ageing. Class discussions included "What is health?", "What is ageing?", "Does the whole body age similarly?" "Can a 30-year-old alcoholic have the liver of a 70-year-old?" We asked open-ended questions stemming from the course content and linked lecture materials to non-lecture activities. Classroom demonstrations used students to emphasize biological complexity. Lectures were also the primary vehicle for introducing the 18 central concepts in biology (National Research Council, 2003) and reinforcing the eight specific concepts referred to earlier (Table 2).

Parts I and II of the lecture series focused on the human organism and a discussion of what constitutes health and illness. Introductory lectures presented the "systems biology" approach and the complexity of studying biology in an integrated fashion; they also presented the course's theme of control and communication, and the concept that the control and communication network is the locus of health and the integrator of the seven

Table 2.

List of Central Concepts in Biology (National Research Council, 2003) for Introduction and Reinforcement in the Biological Concepts of Health Course

1. Understanding biological systems requires both reductionist and holistic thinking; novel properties emerge as simpler units assembled into more complex structures.

2. Biological systems tend towards a steady state in the face of internal or external changes, by the action of complex feedback systems.

3. Living systems are far from thermodynamic equilibrium. They utilize energy, largely derived from photosynthesis, which is stored in high-energy bonds or ionic-concentration gradients. The release of this energy is coupled with thermodynamically unfavourable reactions that drive biological processes.

4. Communication networks within and between cells, and between organisms, enable multicellular organisms to co-ordinate development and function according to their environment.

5. In multicellular organisms, cells divide and differentiate to form tissues, organs, and organ systems with distinct functions. These differences arise primarily from changes in gene expression.

6. Living organisms have behaviour, which in many species can be altered by experiences.

7. Many disease/decay processes arise from the disruption of communication and co-ordination by infection, mutation, chemical insult, trauma, and environmental change.

8. Groups of organisms of the same species grow and interact among themselves within populations, and among populations of the same or other species, to the limits imposed by biotic and abiotic environments. 
dimensions of human health (spiritual, physical, mental, social, emotional, environmental, and occupational). An integrated approach to research and medicine in health was discussed, including the basic experimental models for medical/health-related research, moving from mathematical models, to isolated cells/tissue, to animal models and then human models. We then discussed "approaches" in medicine-from traditional evidencebased medicine to newer approaches, such as evolutionary medicine, integrative medicine, collective medicine, and enhancement medicine. This also raised the discussion of $\mathrm{P} 4$ medicine (personalized, predictive, preventative, participatory). Different dimensions of health were discussed next, using time as an example, and including such concepts as circadian rhythms, change/maintenance over time, the communication amongst different systems, health through ageing, and how this is measured (using effective and noneffective biomarkers). Healthspan and lifespan were also discussed in this module.

Part III of the lecture series focused on the physiological basis for individual health. Lectures on the physiology of nerves, the nervous system, neural communication, hormonal communication, and the local support and defense system (i.e., the immune system) introduced the important physiological components of the control and communication network. The cardiovascular system, the digestive system, and the energy distribution and maintenance systems were described and used to emphasize the communication and co-ordination systems and homeostatic regulation within the body.

Part IV of the lecture series discussed the ideas of homeostasis, allostasis, and stress in order to give students a model of how stresses alter current and future health as well as health throughout the lifespan. We also introduced the concept of physiological complexity and explored how numerous regulators can affect a specific variable, as well as how complexity can be altered.

The lecture series concluded with Part V, in which we considered what factors contribute to health and longevity (internal, external, ageing, genetics), including lifestyle issues associated with cardiovascular disease and Alzheimer's. We ended with summaries of three major theories of ageing, including "use it or lose it", the genetic basis for ageing, and free radical damage/mitochondrial ageing.

The lecture series was supported by a custom textbook that combined content from four textbooks in the areas of health, biology, physiology, and psychology.

Tutorials. Tutorials were designed to continue students' learning about health from a disease perspective while they also developed skills in effective oral and written communication, co-operative group work, and independent learning. Tutorials were intentionally not linked to specific lecture material but instead connected to the course by offering a different venue in which to explore health.

The tutorial structure was designed to provide a small-group learning experience within the large class size. Tutorial groups had 30 students and one teaching assistant (TA) leader per section; these sections stayed together through the nine weeks of the course. Students were organized in groups of five and tasked with researching an assigned disease. Each student was given a specific component of the disease to research, using a provided template. Students were guided through the processes of researching their disease component and preparing their presentation, through weekly meetings with their group and a TA and through a series of homework assignments. Weekly meetings were used to help students navigate through the research process-discussing reputable resources, practic- 
ing reading the primary literature, discussing and practicing information organization, discussing and practicing PowerPoint presentations and oral communication skills, and undergoing peer evaluation. Finally, students prepared and presented a three-minute PowerPoint presentation as part of the group, resulting in a 15-minute group presentation that covered five aspects of the disease. The oral presentation was evaluated by the TA and by each student in the tutorial section. Each student also had to hand in a written text of his/her presentation for grading.

Laboratories. Two three-hour labs were used to develop and assess independent learning skills. Students worked collaboratively but were not assembled in groups for the labs, and independently completed the lab work and assignments. The labs were intentionally not linked to specific lecture material but instead connected with the course by offering a different venue to explore health. Our definition of independent learning was to set your own learning objectives and evaluate your own learning outcomes. The basic strategy to teach and assess independent learning was to not tell students what to learn, just give them a wide range of materials, discuss the information, and then ask them to do a reflective task that drew on what they had been discussing, the materials they had been given, as well as other materials, textbooks, lectures, life experiences, etc. A key component in the teaching and assessment of these labs was that the work and the questions to be answered were not revealed until students attended the lab. The written reflective piece was graded, with grammar and spelling being important components. Therefore, the labs taught and assessed independent learning skills and reinforced writing skills.

$\boldsymbol{L A B} 1$ structure. Seven pre-lab quizzes were assigned in which students gathered personal information (i.e., health, well-being, personality type). Students then brought this information to the lab, where they engaged in a general discussion with the TA about health (psychological, social, physiological). They were then asked to write a mini-essay in response to the question "Are you healthy?" They were not told of this exercise until the end of the lab.

$\boldsymbol{L A B} 2$ structure. Students examined three separate stations containing information on: (i) spinal anatomy and physiology, (ii) spinal imaging and spinal procedures, and (iii) physiological risk factors associated with spinal injury. There was a discussion with the TA about lower back pain, then students were asked to write a mini-essay assessing their own risk for spinal injury. They were not told of this exercise until the end of the lab, and the essay had to be written in lab time.

Online skills workshops to support the learning of each of the eight skills and attributes identified to be taught and tested in the linked-course structure were made available on the course website. The workshops for oral communication skills and independent learning are currently online resources to which students are directed as an important resource but will evolve into a mandatory component of the course, whereby the workshops will contain interactive activities and testable components. The workshops for all eight skills and attributes are available to all students registered in any of the three courses in the linked-course model.

\section{The Interdisciplinary Project}

At week nine of the semester, all course activities ceased, and the students from each of the three courses in the linked-course model were arranged into groups of six, with two students from each course in the linked-course structure and, therefore, students from 
different backgrounds (i.e., two students from the Biological Concepts of Health course, two from the Discovering Biodiversity course, and two from the Molecular and Cellular Biology course). The goals for this project were that students should be able to:

1. Integrate information: In a concerted effort, integrate different biological perspectives (health; molecular and cellular biology; ecology; evolution and physiology) and reflect on how multiple perspectives might influence the students' final position on their topic.

2. Work in teams: Co-ordinate efforts and consider perspectives among members of a student team.

3. Problem solve: Apply problem-solving approaches to critically analyze a multidimensional biological topic.

4. Present a poster: Present their findings via a concept map and text in an accurate, informative, and visually creative manner.

Students were assigned a complex, real-world problem-such as malaria or sustainable agriculture-and given specific issues to think about that would include each of the students' levels of understanding of the topic (molecular to ecological) and require them to use specific tools (concept maps); they then had to impart their information in a poster presentation. The online skills workshops for each of the skills and attributes could be used as a reference for any skill required throughout the independent project and throughout the course.

\section{Pedagogical Validation of the Biological Concepts of Health Course}

Our goal was to design a course to enhance student learning and engagement, develop skills (oral communication and independent learning), emphasize inquiry, and encourage a deeper level of learning. We knew that we had been successful in the first three respects, but had we developed a course that encouraged a deeper level of cognition than the courses that had been replaced (Biology I and Biology II)? In order to assess this component of the course, we used the Blooming Biology Tool (Crowe, Dirks, \& Wenderoth, 2008; Zheng, Lawhorn, Lumley, \& Freeman, 2008) as a course design assessment technique. This tool uses Bloom's Taxonomy of cognitive domains (Bloom, 1956) to categorize expected types of thinking. Bloom's taxonomy categorizes ways of knowing, from lowerorder to higher-order thinking, through six categories-knowledge, comprehension, application, analysis, synthesis, and evaluation-whereby the first two levels are considered lower-order cognitive skills and levels three to six are considered higher-order (Zheng et al., 2008). The level of cognition required for each test question and assignment was assessed to determine the levels of cognition expected through assessment. Our hypothesis was that within the new course, we had significantly increased the level of cognition expected, and we assumed that if the students succeeded in completing the new course, then they had met these higher expectations and had attained the higher level of cognition.

\section{Methods}

We followed the Blooming Biology process as described in Zheng et al. (2008) and Crowe et al. (2008). Briefly, we assigned each of Bloom's cognitive domains a number (knowledge - 1; comprehension - 2; application - 3; analysis -4 ; synthesis -5 ; and eval- 
uation - 6). Each member of the Blooming team independently assessed and assigned a Bloom level (and associated number) to each test question and task of each component of the course in which students were graded. The frequency of the test questions and course components at the six levels of cognition for each graded component in the course was weighted relative to their value in the course, allowing a calculation of a weighted average and totalling $100 \%$ per course.

We had a team of six faculty and teaching staff undergo the Blooming process; they had varying degrees of association with the course and varying amounts of teaching experience. The team went through two normalizing exercises (124 test questions in two different areas, nutrition and exercise science) in order to reach an inter-rater agreement of $80 \%$. Agreement was defined as four out of six raters agreeing on the Bloom level of each question/assignment. In cases where fewer than four raters were in agreement, the Bloom level was assessed as follows: when only three raters agreed, and ratings differed by one (i.e., 1, 1, 1, 2, 2, 2), we took the average and then alternated rounding up and down; when only three raters agreed, and ratings differed by two (i.e., 2, 2, 2, 4, 4, 4), we took the average; when two raters agreed, and ratings were sequential (i.e., 1, 1, 2, 2, 3, 3), we chose the intermediate value.

This process was undertaken for each assessment component for Biology I, Biology II, and the Biological Concepts of Health course. For Biology I there were 145 multiple-choice test questions, three writing assignment activities, and 25 tutorial activities bloomed. For Biology II there were 145 multiple-choice test questions, three writing assignment activities, and one online activity bloomed. For the Biological Concepts of Health there were 203 multiple-choice test questions, eight tutorial activities, two lab activities, and one interdisciplinary project activity bloomed. This produced a Bloom's profile for each course whereby an average Bloom's level for the entire course could be calculated.

Average Bloom levels were compared using a students $t$ test, wherein significant difference was assumed when $\mathrm{p}<0.05$.

\section{Results}

The average Bloom's level for the entire Biological Concepts of Health course was $3.28 \pm 0.2$, with an inter-rater agreement of $86 \%$. This Bloom's level was significantly greater than for Biology I (average Bloom level 1.93 \pm 0.1 , inter-rater agreement 79.4\%) but not significantly different from that of Biology II (average Bloom level 2.95 \pm 0.1 , inter-rater agreement $86.4 \%$ ). Figure 4 shows the Bloom profile for each course. The Biological Concepts of Health course had approximately $55 \%$ of the course activities ranked at lower-order cognitive levels and $45 \%$ in the higher-order domains. This profile was different from that of Biology I, wherein approximately $89 \%$ of the course activities ranked at lower-order cognitive levels and $11 \%$ in the higher-order domains, but was similar to that of Biology II, wherein approximately $60 \%$ of the course activities ranked at lower-order cognitive levels and $40 \%$ in the higher-order domains. Therefore, the higher Bloom level for Biology II stemmed from activities being ranked in higher-order cognitive domains and from these activities being assigned a heavier weighting in determining the students' final grades. 


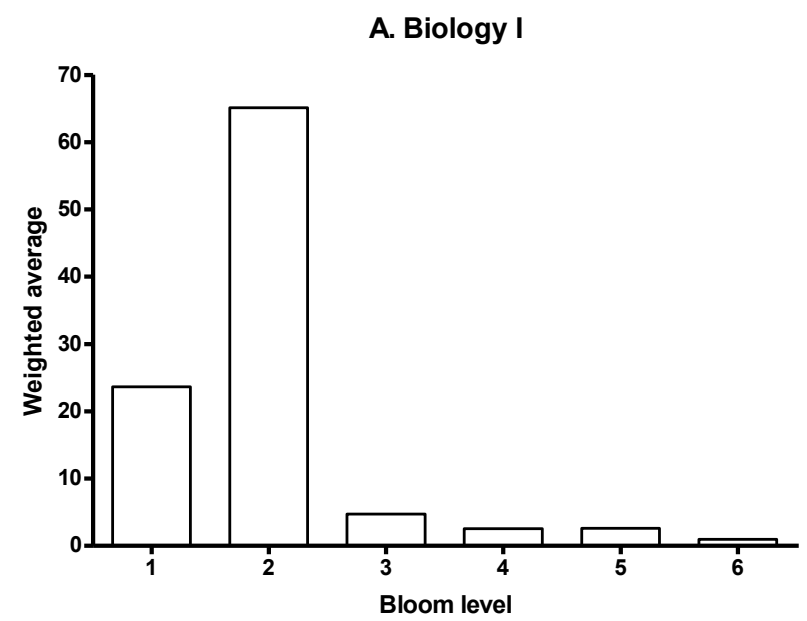

B. Biology II
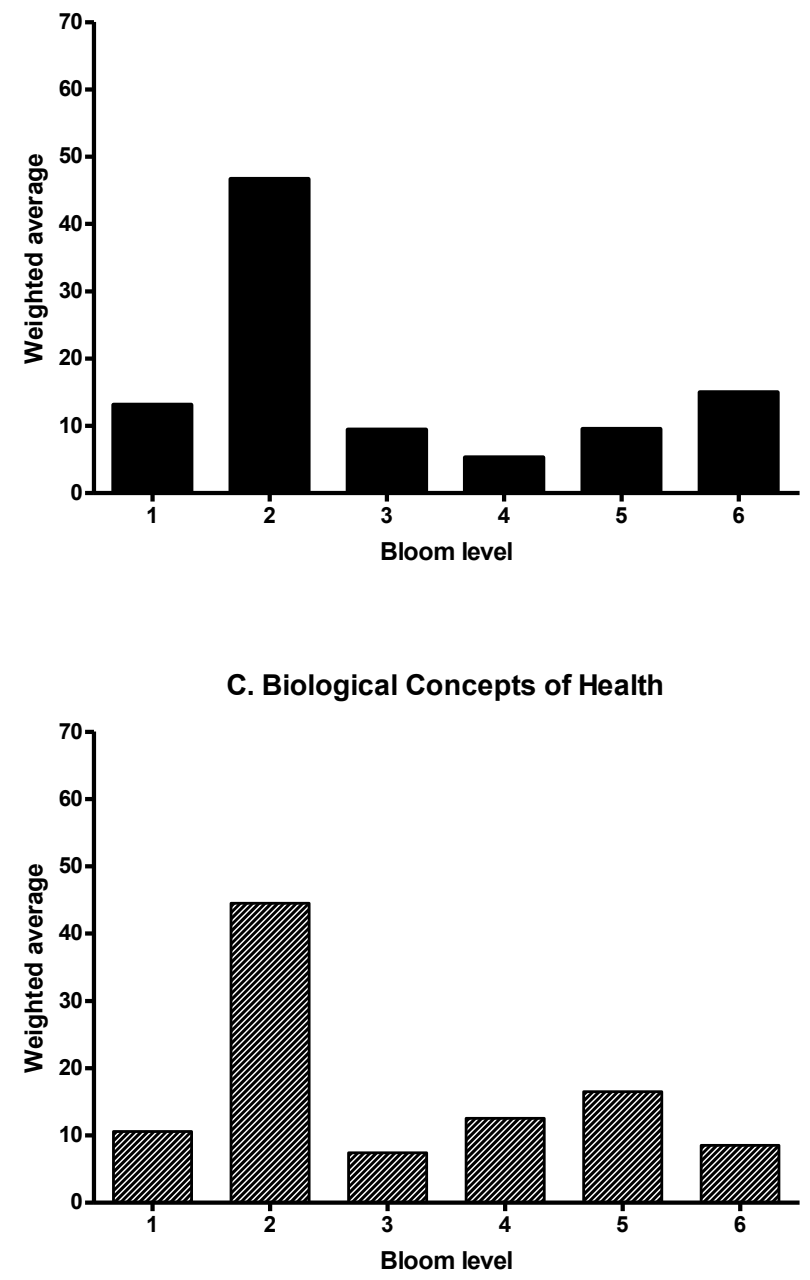

Figure 4. Blooming profiles for all components of each course. The frequency of all test questions and assessed course components, at the six levels of learning as defined in Bloom's taxonomy, for (A) Biology I, (B) Biology II, and (C) the Biological Concepts of Health Course. The frequency of each graded component in each course was weighted relative to its value in the course, for a total of $100 \%$ per course. 
Further breakdown of the distribution of the Bloom levels among the test and skills portions of the courses indicated that the major difference between the courses lay within the skills component. The average Bloom level for the test component in the Biological Concepts of Health course (2.14 \pm 0.05$)$ was not significantly different from the average Bloom level for either Biology I (1.97 \pm 0.08$)$ or Biology II (2.24 \pm 0.08$)$. Figure 5 shows the Bloom profile for tests given in the course in the form of multiple-choice midterm and final exam questions. Biological Concepts of Health had a significant portion of the test questions ranked in the lower-order cognitive domains (84.3\%) and only $15.7 \%$ ranked in the higher-order cognitive domains: $14.7 \%$ were ranked at level 3 and 1.1\% at level 4 , with no higher-ranked questions. This was a very similar profile to Biology I, with $10.7 \%$ of the test questions ranked in the higher-order domains, but both were lower than Biology II, which had $22.5 \%$. These data show that each course was very similar regarding the level of cognition expected for the multiple-choice testing portion of the course. Although the multiple-choice test profiles were similar between courses, the tests' contribution to the overall Bloom profile was less for the Biological Concepts of Health course because they constituted only 50\% of the course assessment, compared to $71 \%$ in Biology I and 67\% in Biology II (see Figures 1 and 3).

The average Bloom level for the skills component in the Biological Concepts of Health course (4.88 \pm 0.1$)$ was significantly different from the average Bloom level for Biology I (1.98 \pm 0.1$)$ but not significantly different from that of Biology II (4.28 \pm 0.2$)$. Figure 6 presents the Bloom profiles for assessment associated with the skills component of the courses. These data show marked differences between Biology I on the one hand and the Biology II and Biological Concepts of Health courses on the other. In the Biological Concepts of Health course, only a minimal portion of the skills component (approximately 6.5\%) was assessed as requiring lower-order cognitive tasks, compared to approximately 93.5\% higher-order. In contrast, $88.6 \%$ of the skills tasks in Biology I required lowerorder cognition and 11.4\% higher-order. The Biological Concepts of Health course was closer to the Biology II course, with $24.2 \%$ of the skills assessed as lower-order and $72.8 \%$ as higher-order. The higher-order cognition required for the skills component in the Biological Concepts of Health course had a larger contribution to the overall Bloom profile, given that this component comprised $50 \%$ of the assessment within the course-substantially more than in Biology I (29\%) and Biology II (33\%).

In order to determine whether we had encouraged higher-order learning, we had to design a course that expected higher-order learning, then show that students could meet this expectation. We compared the class averages and the failure rates for multiple offerings of Biology I, Biology II, and the Biological Concepts of Health course to determine whether students were meeting the higher-order learning expectations imposed in the new course. Further, since the higher-order cognition components resided in the skills component, we looked at the average for the test component (predominantly lower-order cognition expectations) along with the skills component (predominantly higher-order cognition expectations). We found that the new course had an overall class average that was higher and a failure rate that was significantly lower than for either Biology I or Biology II (see Table 3). Further, within the higher overall class average in the Biological Concepts of Health course, the skills component had a higher class average than the testing component (see Table 4), indicating that students were meeting the expectations in the part of the course that demanded higher-order cognition. 
A. Biology I - tests

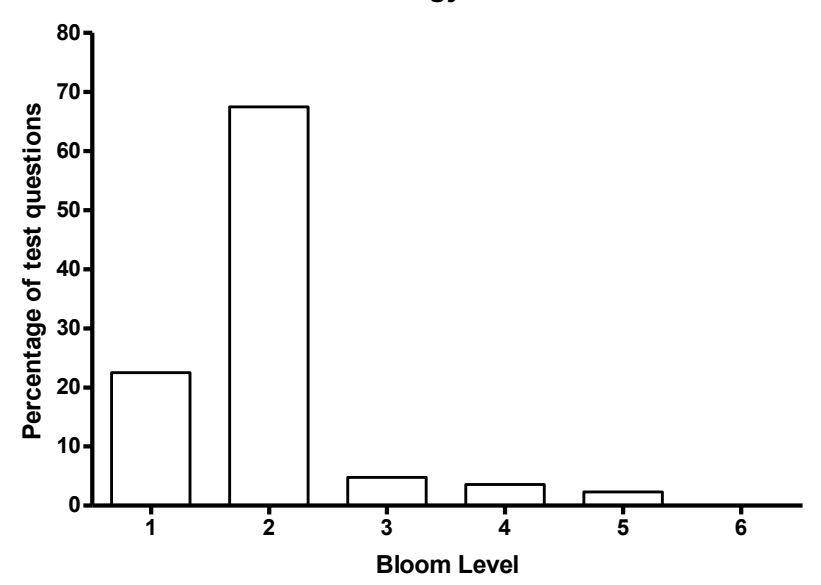

B. Biology II - tests

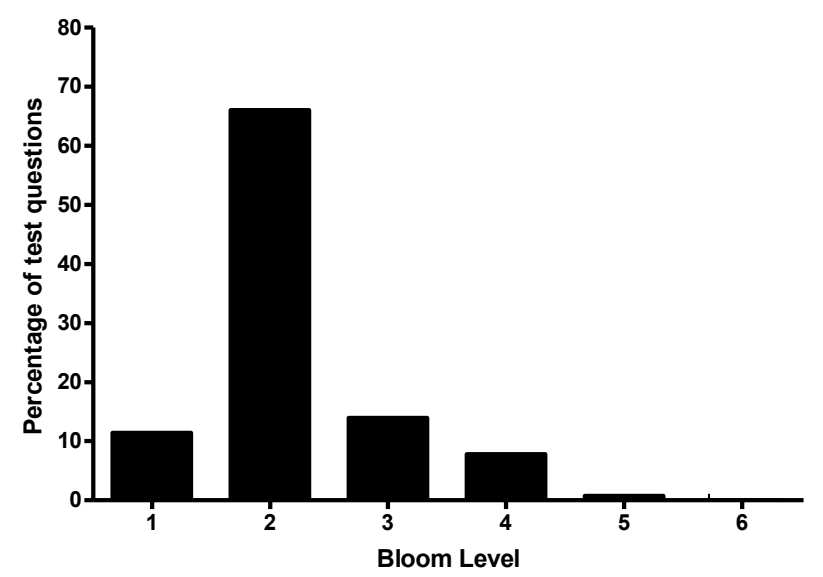

C. Biological Concepts of Health - tests

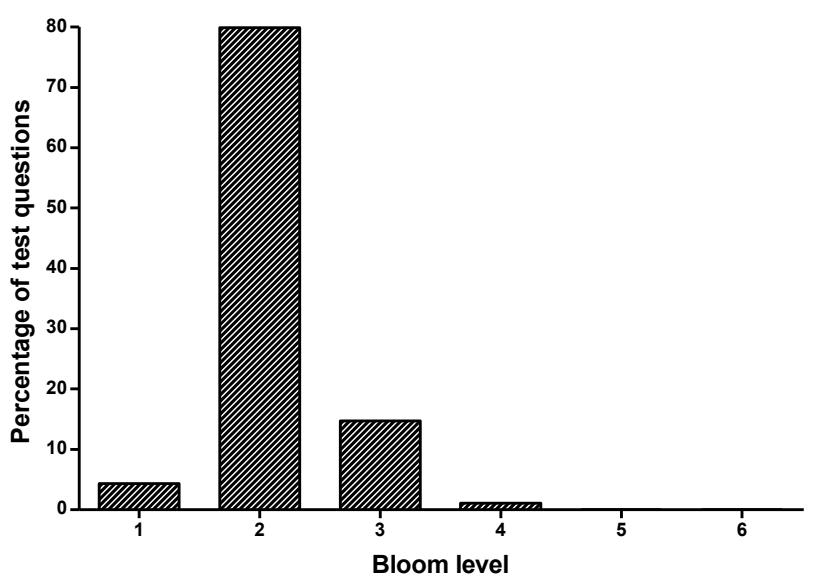

Figure 5. Blooming profiles for the test component of each course. The frequency of all test questions only, at the six levels of learning as defined in Bloom's taxonomy, for (A) Biology I, (B) Biology II, and (C) the Biological Concepts of Health Course. The frequency of each graded component in each course was weighted relative to its value in the course and is represented as a percentage of that subtotal. 


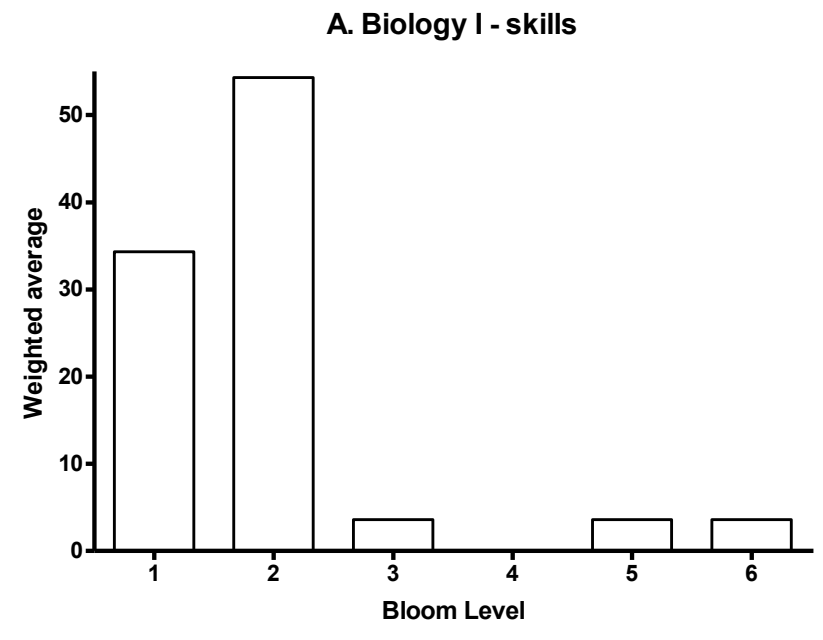

B. Biology II - skills

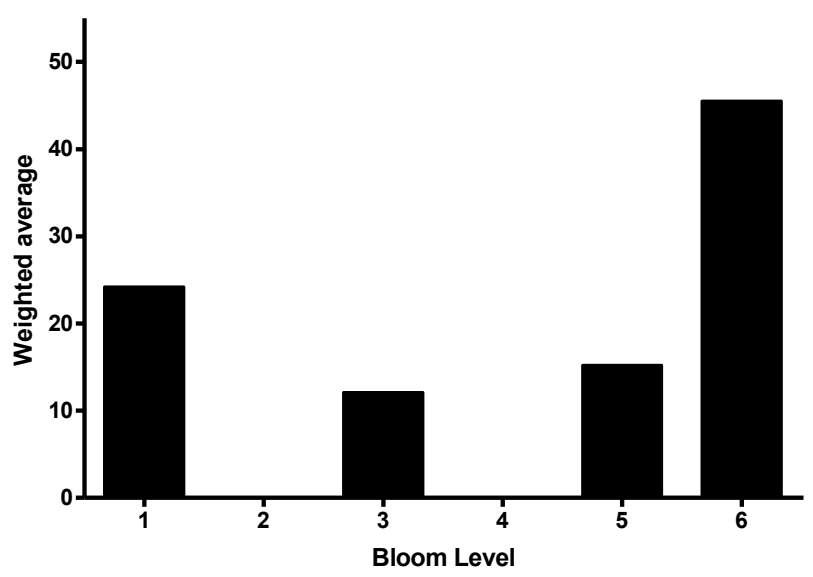

C. Biological Concepts of Health - skills

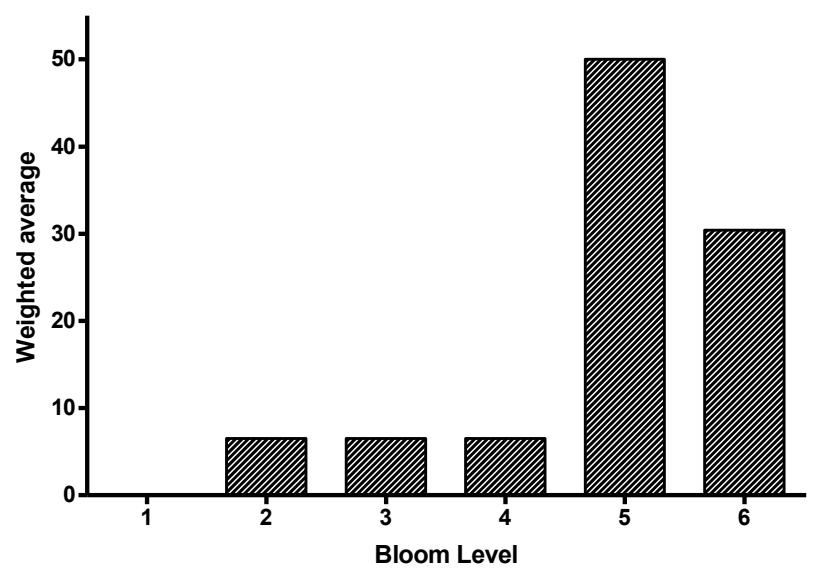

Figure 6. Blooming profiles for skills-related components of each course. The frequency of all assessed skills-related course components and activities, at the six levels of learning as defined in Bloom's taxonomy, for (A) Biology I, (B) Biology II, and (C) the Biological Concepts of Health course. The frequency of each graded component in each course was weighted relative to its value in the course and is represented as a percentage of that subtotal. 
Table 3.

Class Averages and Failure Rates for Eight Offerings of the Biology of Health Course and Seven Offerings of Biology I and Biology II

\begin{tabular}{lccccccc}
\hline & \multicolumn{3}{c}{ Class Average } & & \multicolumn{3}{c}{ Failure Rate } \\
\cline { 2 - 3 } $\begin{array}{l}\text { Different } \\
\text { Semesters }\end{array}$ & $\begin{array}{c}\text { Biology of } \\
\text { Teaken }\end{array}$ & $\begin{array}{c}\text { Biology I } \\
(\%)\end{array}$ & $\begin{array}{c}\text { Biology II } \\
(\%)\end{array}$ & & $\begin{array}{c}\text { Biology of } \\
\text { Health } \\
(\%)\end{array}$ & $\begin{array}{c}\text { Biology I } \\
(\%)\end{array}$ & $\begin{array}{c}\text { Biology II } \\
(\%)\end{array}$ \\
\hline 1 & 76.24 & 67.57 & 66.11 & & 0.75 & 1.1 & 4.3 \\
2 & 75.97 & 65.00 & 64.00 & & 0.32 & 3.0 & 9.0 \\
3 & 77.04 & 62.00 & 68.00 & & 0.69 & 10.5 & 2.0 \\
4 & 76.81 & 67.00 & 70.00 & & 1.23 & 1.6 & 1.1 \\
5 & 74.00 & 62.00 & 69.00 & & 1.29 & 9.7 & 2.5 \\
6 & 72.38 & 67.00 & 65.00 & & 1.18 & 1.8 & 5.0 \\
7 & 75.12 & 60.00 & 67.60 & & 0.60 & 5.5 & 3.6 \\
8 & 75.33 & & & & 0.91 & & \\
Average \pm SE & $75.4 \pm 0.5^{*}$ & $64.4 \pm 1.1$ & $67.1 \pm 0.8$ & & $0.9 \pm 0.1^{\dagger}$ & $4.7 \pm 1.5$ & $3.9 \pm 1.0$ \\
\hline
\end{tabular}

* indicates a significant difference between the Biology I and Biology II class averages.

t indicates a significant difference between the Biology I and Biology II failure rates.

Table 4.

The Class Averages of the Test Component and Skills Components of the Biology of Health Course

\begin{tabular}{|c|c|c|c|c|}
\hline \multirow[b]{2}{*}{$\begin{array}{l}\text { Different } \\
\text { Semesters } \\
\text { Taken }\end{array}$} & \multirow[t]{2}{*}{$\begin{array}{c}\text { Tests } \\
(\text { Worth 50\%)* } \\
\end{array}$} & \multicolumn{3}{|c|}{$\begin{array}{c}\text { Skills } \\
\text { (Worth 45\%) }\end{array}$} \\
\hline & & $\begin{array}{c}\text { Tutorials } \\
\text { (Worth 25\%) }\end{array}$ & $\begin{array}{c}\text { Labs } \\
\text { (Worth 10\%) }\end{array}$ & $\begin{array}{c}\text { Interdisciplinary } \\
\text { Project (Worth 10\%) }\end{array}$ \\
\hline 1 & 70 & 87 & 78 & 72 \\
\hline 2 & 66 & 78 & 84 & 78 \\
\hline 3 & 70 & 82 & 85 & 80 \\
\hline 4 & 65 & 82 & 81 & 79 \\
\hline 5 & 74 & 80 & 82 & 75 \\
\hline 6 & 68 & 83 & 82 & 79 \\
\hline 7 & 72 & 84 & 80 & 77 \\
\hline 8 & 68 & 84 & 83 & 79 \\
\hline Average $\pm \mathrm{SE}$ & $69.1 \pm 1.1$ & $82.5^{ \pm 1.0^{\dagger}}$ & $81.9 \pm 0.8^{\dagger}$ & $77.4 \pm 0.9^{\dagger}$ \\
\hline
\end{tabular}

* There is another test component, worth $5 \%$, which is a biochemistry quiz students take in the first week of classes to give them feedback as to whether they require remedial biochemistry instruction; the average score on this quiz ranges between 86 and $91 \%$ (average $\pm \mathrm{SE}=88.5 \pm 0.5 \%$ ).

$\dagger$ indicates a significant difference from the test component. 


\section{Discussion}

This study reports the design of a new, first-year introductory biology course and shows how the Blooming Biology Tool can be used to understand and assess newly designed courses. We used this tool to show that we had developed a new course that demanded a deeper level of cognition than its predecessors, and we found that students were successful at meeting these higher expectations; we therefore conclude that we developed a course that encouraged a deeper level of cognition. Further, analysis of the newly developed course using Blooming metrics allowed us to make evidence-based decisions about future improvements to the course.

With the Blooming metrics we were able to show that the newly developed course was assessing students at a significantly higher level of cognition than at least one of the courses that it replaced. We found that the average Bloom level for the entire Biological Concepts of Health course was $3.28 \pm 0.2$, which was significantly greater than for Biology I (1.93 \pm 0.1$)$ and higher than but not significantly different from the value for Biology II (2.95 \pm 0.1$)$. Further, the profile for the new course showed more higher-order learning expectations than other large, multi-section, first-year biology courses at other universities, such as the undergraduate courses reported by Zheng et al. (2008) (which yielded a weighted Bloom average of 2.43 \pm 0.14 ) and first-year biology courses from different types of institutions, as reported by Momsen, Long, Wyse, and Ebert-May (2010) (which ranged from $1.43 \pm 0.05$ to $1.95 \pm 0.10$ ). The overall Bloom ranking of the Biological Concepts of Health course was higher than these averages; thus, we can conclude that we have developed a course that requires a higher level of cognition than the courses that it replaced and than courses typically offered at similar institutions. We therefore show that we have developed a course that offers a unique learning experience amongst first-year introductory biology courses.

Further, exploration of the various components of our course using the Blooming Biology Tool indicated that we could attribute the higher average Bloom level in the Biological Concepts of Health course to the ranking of the skills component (4.88 \pm 0.1$)$ rather than to the testing component (2.14 \pm 0.05$)$. We split our Bloom profile into the important assessment elements-the content component and the skills component-to determine their individual profiles and gain a better understanding of whether both components were assessing students at similar levels of cognition. We determined that the content component expectations were at a lower-order level, while the skills were assessed at higher-order levels of cognition. Thus, even though we wanted the lecture portion to enhance a deeper level of cognition, we were not expecting this higher-order cognition in the assessment of the course content. Interestingly, within our own course, the expectation of the level of cognition for course content was very different than the expectation for the skills component. Between courses, we show that our tests have a Bloom profile similar to that of the courses we replaced, indicating that the level of cognition required for our multiple-choice tests is either lower than or no higher than in the previous courses. Further, we show that the Bloom profile for the skills portion of the new course was much higher than for the skills component of Biology I but not significantly higher than for Biology II. Thus, the major differentiation between the courses occurs at the skills level. Further, the Biological Concepts of Health course weights the skills component higher overall (50\% of 
the course mark) than either Biology I (25\%) or Biology II (25\%). So, the average Bloom level is higher for Biological Concepts of Health because the skills component is ranked higher and is more heavily weighted.

The expectation of a higher level of cognition has been correlated to a deeper level of learning (Newton \& Martin, 2013). Our data also support this correlation. Our hypothesis was that within the new course, we had significantly increased the level of cognition expected as compared to the courses it replaced, and we assumed that if the students were successful at completing the new course, then they had met these higher expectations and had attained this higher level of cognition. Indeed, we found that the Biological Concepts of Health course had a higher overall class average and a lower failure rate than the courses it replaced. Further, within the higher overall class average in the new course, the skills component, where we had the highest expected levels of cognition, had a higher class average than the testing component, which had lower expected levels of cognition. Therefore, students were meeting the higher expectations in the parts of the course that demanded higher-order cognition. Thus, we conclude that we were successful in developing a course that encouraged a deeper level of learning in our students.

The Bloom assessment allows us to now focus our energies on adjusting those parts of the course that need to be changed to meet our course goals. Our data indicated that the expectation of the level of cognition for the content portion could be raised to more closely match the level of cognition expected within the skills component. Test questions could be written to better reflect our interest in creating a course with a greater emphasis on higher cognitive levels; thus, we need to focus on the multiple-choice tests in order to improve our course's required cognition level. The ideal Bloom profile for a first-year biology course is not known. Certainly, we might not expect that a first-year introductory course would be optimal, or at least better, if it were shifted rightward to be all sixes; rather, in an introductory course for first-year students, where content delivery is an important component, we might expect a leftward component. It is possible that the rightward shift might best be built across the curriculum, moving rightward from first to fourth year. The important issue is that with the Blooming Biology Tool, courses can be specifically designed to meet any degree of lower- or higher-order learning, and then programs can be built in an evidence-based manner. Thus, with this tool, program curricula can be planned using evidence-based decisions, ensuring that the curriculum within a given program is designed to deliver the intended content and skills.

The enrichment of the course to include higher-order cognition did not come without its costs. The labs and tutorials were the components of the course where the skills were taught and assessed, and where the higher-order levels of cognition were assessed. The delivery and assessment of the skills component of labs and tutorials in this course required support from a full-time teaching staff member and 24 TAs, at a cost of $\$ 186,754$ per year for 1,800 students. Thus, the cost of higher-order levels of cognition for large numbers of students is high and must be considered in course design. Within the current Biological Concepts of Health course, the Bloom level can be increased at a relatively low cost, as only the test questions need to be adjusted, but for courses in which skills components have to be added, cost will be a significant factor.

In conclusion, we have designed a course that successfully delivers the fundamentals of biology teaching through the vehicle of health. The course is structured to effectively emphasize inquiry, teach oral communication and independent learning skills, and 
encourage a deeper level of learning in a large, multi-section, first-year course. Using the Blooming Biology assessment tool, we have shown that this course offers a deeper cognitive experience than the courses that it replaced. We can now move forward, in an evidence-based manner, to change components of the course so as to offer an even richer first-year learning experience.

\section{References}

Bloom, B. S. (1956). Taxonomy of educational objectives: The classification of educational goals. New York, NY: David McKay.

Crowe, A., Dirks, C., \& Wenderoth M. P. (2008). Biology in Bloom: Implementing Bloom's taxonomy to enhance student learning in biology. Cell Biology Education: Life Sciences, 7, 368-381.

Desmarais, S. (2012). University of Guelph learning outcomes. Retrieved from http://www.uoguelph.ca/vpacademic/avpa/outcomes/pdfs/Senate\%2oReport\%20 (December\%205,\%202012).pdf

Kenny, N., \& Desmarais, S. (2012). A guide to developing and assessing learning outcomes at the University of Guelph. Retrieved from http://www.uoguelph.ca/ vpacademic/avpa/pdf/LearningOutcomes.pdf

Momsen, J. L., Long, T. M., Wyse, S. A., \& Ebert-May, D. (2010). Just the facts? Introductory undergraduate biology courses focus on low-level cognitive skills. Cell Biology Education: Life Sciences, 9, 435-440.

Murray, J., \& Summerlee, A. (2007). The impact of problem-based learning in an interdisciplinary first-year program on student learning behaviour. Canadian Journal of Higher Education, 37, 87-107.

National Research Council. 2003. Bio2010: Transforming undergraduate education for future research biologists. Washington, DC: The National Academies Press.

National Survey of Student Engagement. 2008. Promoting engagement for all students: The imperative to look within. Bloomington, IN: Indiana University Center for Postsecondary Research.

Newton, G., \& Martin, E. (2013). Blooming, SOLO taxonomy, and phenomenography as assessment strategies in undergraduate science education. Journal of College Science Teaching, 43, 82-94.

Zheng, A. Y., Lawhorn, J. K., Lumley, T., \& Freeman, S. (2008). Assessment: Application of Bloom's taxonomy debunks the MCAT myth. Science, 319(5862), 414-415.

\section{Contact Information}

Coral L. Murrant

Department of Human Health and Nutritional Science

University of Guelph

cmurrant@uoguelph.ca 
Coral Murrant is an associate professor in the Department of Human Health and Nutritional Sciences at the University of Guelph. She teaches a large third-year Human Physiology class. Her research interests are two-pronged: (1) the relationship between active tissue and the microvasculature that ensures adequate delivery of blood flow to the tissue and (2) evidence-based course assessment to better align a course's structure and assessment with its learning outcomes. She is particularly interested in improving the assessment practices in large classes.

David Dyck is a professor in the Department of Human Health and Nutritional Sciences at the University of Guelph. He teaches in the first-year Biological Concepts of Health course as well as a fourth-year Regulation of Metabolism course, and also co-ordinates the capstone literature review and experiential research courses. His research interests lie in the regulation of fat and carbohydrate metabolism in skeletal muscle, with a particular emphasis on the dysregulation that occurs in obesity and diabetes.

Jim Kirkland is a professor in the Department of Human Health and Nutritional Sciences at the University of Guelph. He teaches in the first-year Biological Concepts of Health course, a large, third-year Fundamentals of Nutrition course, and a fourth-year toxicology course. His research interests lie in the effects of niacin deficiency on DNA repair rates, apoptosis, the progression of leukemia in response to carcinogen exposure, and the impact of niacin status in animal models of learning and behaviour.

Genevieve Newton is an assistant professor in the Department of Human Health and Nutritional Sciences at the University of Guelph. Her research in the fields of teaching, learning, and knowledge transfer spans several areas, including case-based learning, educational technologies, student assessment, and knowledge mobilization. The overall objective of her work is to identify strategies that can be used to enhance the learning experience, to facilitate a deep approach to learning, and to effectively communicate health knowledge to targeted populations.

Nicolette Richardson is an assistant professor in the School of Kinesiology and Health Science at York University in Toronto, Ontario. She is a former course co-ordinator of the Biological Concepts of Health course at the University of Guelph, where she also completed her PhD work. Nicolette's research focuses on educational strategies for teaching human anatomy and physiology, with an emphasis upon online learning.

Kerry Ritchie is an assistant professor in the Department of Human Health and Nutritional Sciences at the University of Guelph. She is a former course co-ordinator of the Biological Concepts of Health course. Her scholarship of teaching and learning research focuses on strategies for teaching critical thinking and communication skills in health sciences education, with special attention to novel methods for scaling these practices to suit large classes.

Justine Tishinsky is a teaching technician and lecturer in the Department of Human Health and Nutritional Sciences at the University of Guelph. She is the co-ordinator of the 
Biological Concepts of Health course. Justine is also an instructor in the first-year seminar program, offering a course on the Art and Science of Sleep. Finally, she serves as an advisor for kinesiology students at the University of Guelph-Humber in their fourth-year literature review course. Justine's research interests include improving student learning outcomes by generating means to foster the development of higher-order thinking skills.

Bill Bettger is a professor in the Department of Human Health and Nutritional Sciences at the University of Guelph. He teaches in the Biological Concepts of Health course, applied nutrition courses at the undergraduate and graduate levels, and a course on teaching, learning, and knowledge transfer. His research focus is two-pronged: (1) nutrition research on nervonic acid and other very long chain fatty acids in sphingomyelin and (2) scholarship in teaching, learning, and knowledge transfer in the life and health sciences, with expertise in (i) curriculum design, (ii) community-engaged, project-based learning, and (iii) creativity. 